\title{
Gonadal Changes during the Annual Reproductive Cycle of the Ascidian Halocynthia aurantium (Pallas)
}

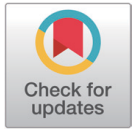

Received: August 7, 2021

Revised: October 16, 2021

Accepted: November 19, 2021

${ }^{+}$Corresponding author

Gil Jung Kim

Dept. of Marine Molecular Bioscience,

Gangneung-Wonju National University,

Gangneung 25457, Korea.

Tel: +82-33-640-2415

Fax: +82-33-640-2849

E-mail:gjkim@gwnu.ac.kr

Copyright $\odot 2021$ The Korean Society of Developmental Biology.

This is an Open Access article distributed under the terms of the Creative Commons Attribution Non-Commercial License (http://creativecommons.org/licenses/ by-nc/4.0/) which permits unrestricted non-commercial use, distribution, and reproduction in any medium, provided the original work is properly cited.

ORCID

Wang Jong Lee

https://orcid.org/0000-0003-2152-8915

Gil Jung Kim

https://orcid.org/0000-0001-6441-2694

Conflict of interests

The authors declare no potential conflict of interest.

Acknowledgements

Not applicable.

Authors' contributions

Conceptualization: Lee WJ, Kim GJ.

Data curation: Lee WJ, Kim GJ.

Investigation: Lee WJ.

Writing-original draft: Kim GJ.

Writing-review \& editing: Lee WJ, Kim GJ.

\section{Ethics approval}

This article does not require IRB/IACUC approval because there are no human and animal participants.

\author{
Wang Jong Lee and ${ }^{\dagger}$ Gil Jung Kim \\ Dept. of Marine Molecular Bioscience, Gangneung-Wonju National University, Gangneung 25457, Korea
}

\begin{abstract}
The ascidian Halocynthia aurantium (sea peach), a marine invertebrate, belongs to the same genus of the phylum Chordata along with the ascidian Halocynthia roretzi (sea pineapple), which is one of the model animals in the field of developmental biology. The characteristics of development and reproduction of $H$. aurantium are not yet known in detail. In order to find out the spawning period of $\mathrm{H}$. aurantium, we investigated development of the gonads during the annual reproductive cycle. Testis and ovary were both in the bisexual gonads (ovotestes) of $H$. aurantium, which is a hermaphrodite like $H$. roretzi. In $H$. aurantium, the right gonad was longer and slightly larger than the left gonad throughout the year. In each gonad, the number of the testis gonoducts was slightly higher than that of the ovary gonoducts. These features were similarly observed in $\mathrm{H}$. roretzi. However, the number of the testis gonoducts and the ovary gonoducts in each gonad of $H$. aurantium was about half that of $H$. roretzi. The gonads of $H$. aurantium contracted during the winter and summer seasons. The gonads decreased to the smallest size around February, and then started to increase again in March. The gonads were most developed in September of the year. Therefore, it is estimated that the spawning of $H$. aurantium begins around this period.
\end{abstract}

Keywords: Ascidian, Halocynthia aurantium, Bisexual gonad, Spawning period

\section{INTRODUCTION}

Ascidians, also known as tunicates or sea squirts, are classified as chordates along with vertebrates because their tadpole-shaped larvae possess a notochord in the tail and a dorsal nerve cord (Kowalevsky, 1866; Katz, 1983; Nishida 2005; Lemaire, 2009). Ascidians are mainly consumed in Asia, Chile and the Mediterranean, where product is sourced from both the wild and, in the case of the Halocynthia and Styela species in high demand, from cultured populations (Nguyen et al., 2007; Lambert et al., 2016). The ascidian $H$. roretzi (sea pineapple) is not only one of the model animals in the field of developmental biology but also one of the major aquaculture varieties in Korea and Japan (Shenkar \& Swalla, 2011). However, the farmed fishermen are experiencing a lot of difficulties because of the mass death of $H$. roretzi due to increase in water temperature, changes in the environment, and outbreak of the disease such as soft tunic syndrome (Kumagai et al., 2011; Kim et al., 2014; Shin et al., 2014).

The ascidian $H$. aurantium (sea peach) is a marine invertebrate belonging to the same genus of chordates with $H$. roretzi. It has been reported that $H$. aurantium inhabits the northern part of the East 
Sea, the Sea of Okhotsk, the Bering Sea, and the Gulf of Alaska in the Pacific Ocean (Van Name, 1945). In Korea, it is generally distributed up to the coast of Sokcho, and there is a report that it was also collected from the coast of Samcheok, Gangwon-do (Rho \& Lee, 1991). Its usual range in depth is from about 10 to $100 \mathrm{~m}$, but it is estimated that it mainly inhabits at a depth of 10 to $40 \mathrm{~m}$ on the coast of Gangwon-do.

H. aurantium is a strong candidate, as a new cultivated variety of ascidian species. H. aurantium and $H$. roretzi resemble each other not only in taste but also in many characteristics of food product. They are presumed to be similar in biological characteristics. However, the reproduction of $H$. aurantium is not well known despite some studies on the physiology, the early development, and the mitochondrial genome (Inazawa et al., 1998; Kim, 2020; Kim et al., 2021). In this study, we investigated gonadal changes during the annual reproductive cycle of the ascidian H. aurantium.

\section{MATERIALS AND METHODS}

Adults of ascidians, H. aurantium (Pallas) and H. roretzi (Drasche), were collected in the sea near Sokcho, Gangwon-do, Korea from July 2015 to October 2016. To calculate the gonadosomatic index (GSI: gonad weight/body weight $\times 100$ ) of $H$. aurantium, the weight of the body and the gonad was measured using 10 individuals every month. The average size of $H$. aurantium and $H$. roretz $i$ adults used in the experiment was $230 \mathrm{~g}$ and $250 \mathrm{~g}$, respectively. The gonads were obtained by incision on the dorsal side (Atrial siphon side) of the Adults (Fig. 1).

\section{RESULTS AND DISCUSSION}

\section{Characteristics of the bisexual gonad of $H$. aurantium}

In adult of $H$. aurantium, the attached side is the posterior of the body. On the upper, the anterior side has an incurrent oral (branchial) siphon and an outcurrent atrial siphon (Fig. 1A). Oral siphon is
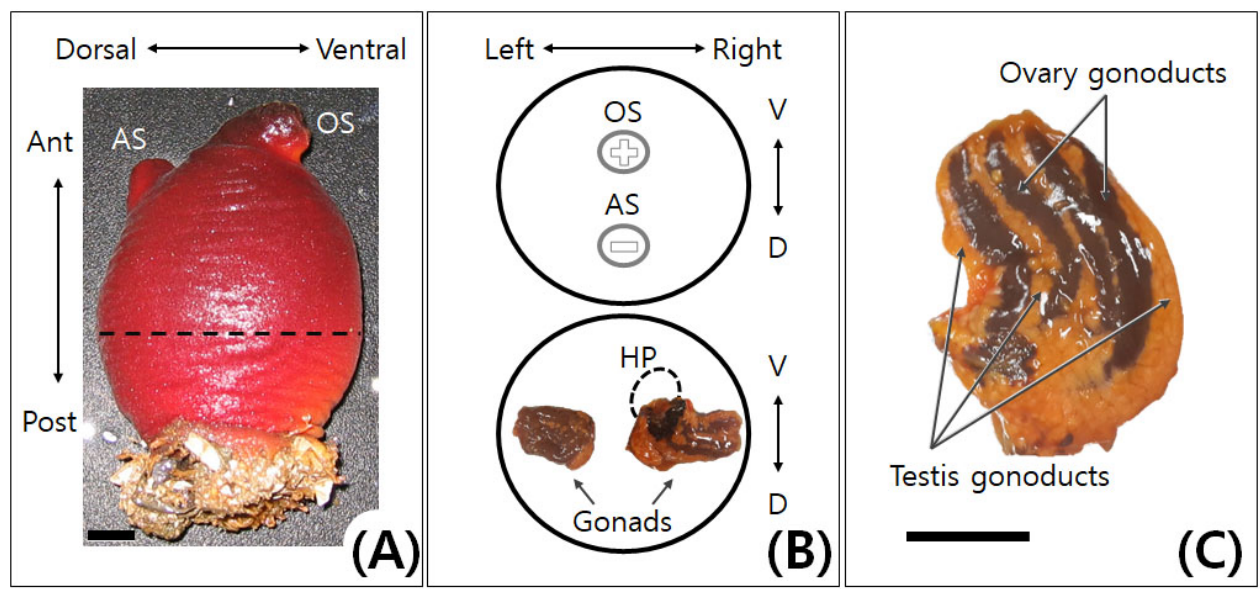

Fig. 1. The ascidian Halocynthia aurantium. (A) An adult with an incurrent oral siphon (OS) and an outcurrent atrial siphon (AS). Lateral view. Anterior is up and posterior is down. OS is on the ventral side. (B) Upper and lower diagrams illustrate a view of the adult from above and a transverse section which made along a broken line indicated in A, respectively. The hepatopancreas (HP, a circle of broken line) is located on the right with a gonad. (C) A bisexual gonad with the gonoducts of testis and ovary. D, dorsal; V, ventral (Scale bars $=2 \mathrm{~cm}$ ). 
located on the ventral side. When siphons are closed, oral siphon is cross-shaped, whereas atrial siphon is rod-shaped (Fig. 1B). Adult of the ascidian H. aurantium is a hermaphrodite like that of $H$. roretzi. The bisexual gonad of $H$. aurantium was a type of the ovotestes in which testis and ovary coexist (Fig. 1C). In H. aurantium, the right gonad was longer and slightly larger than the left gonad throughout the year (Fig. 1B, lower diagram). The hepatopancreas was attached only to the right gonad. In each gonad of $H$. aurantium, the number of the testis gonoducts was slightly higher than that of the ovary gonoducts (Table 1). Moreover, the number of the testis and ovary gonoducts in each gonad of $H$. aurantium was about half that of the $H$. roretz $i$. The gonoducts of testis and ovary were alternately located in the bisexual gonad, and the testis gonoducts were mainly located on both edges of the gonad (Fig. 1C). When the gonads were reduced, the testis gonoducts atrophied earlier than the ovary gonoducts (data not shown). These features were similarly observed in $H$. roretzi (Kim et al., 2001).

\section{Seasonal changes in the bisexual gonads}

To find out the spawning period of H. aurantium, we investigated development of the gonads during the annual reproductive cycle. Development of the gonads was determined using GSI . GSI of H. aurantium showed the highest level in September 2015, and then gradually decreased to the lowest level in February of the following year (Fig. 2). The GSI has gradually increased since March, and reached the highest level again in September. The average GSI in September, the highest level, was about 3.8 times higher than that in February, the lowest level. It seems to be that the gonads of H. aurantium contracted from winter to next summer seasons. The gonads decreased to the smallest size around February, and then started to increase in March. The gonads were most developed in September in both 2015 and 2016. Therefore, it is likely that the spawning period of H. aurantium begins around September.

As in the case of many marine animals, the spawning of ascidians is known to be affected by the photoperiod and water temperature, so there is a difference depending on the habitat (Bates, 2011; Shenkar \& Swalla, 2011). In the East Sea of Gangwon-do, the spawning period of $H$. roretzi has been reported between December and February (Kim et al., 2001). It was reported that the spawning of $H$. hilgendorf ritteri living in the sea near Jeju Island occurs from November to January (Choi et al., 2004). These two species belonging to the Halocynthia genus are a type of winter breeder. In contrast, $H$. aurantium appears to spawn in autumn. There is a possibility that the spawning periods of $H$. aurantium is likely to vary slightly depending on the depth of the habitat. The water temperature at a depth of $10 \mathrm{~m}$ and $30 \mathrm{~m}$ differs by more than 10 degrees depending on the season. Thus, it is important to know the habitat depth of H. aurantium used in the experiment, but it is very difficult to collect only the individuals of a certain depth in the current situation where aquaculture is not possible. There can be a difference in the spawning periods of H. aurantium living a depth of $10 \mathrm{~m}$ and a depth of $30 \mathrm{~m}$ or less, but the difference will not be very large. Therefore, these results will be useful for future studies on the development and reproduction of $H$. aurantium.

Table 1. The average number of the testis gonoducts and the ovary gonoducts in each bisexual gonad of ascidians Halocynthia aurantium and Halocynthia roretzi

\begin{tabular}{lccccc}
\hline \hline & \multicolumn{2}{c}{ Gonad on the right } & & \multicolumn{2}{c}{ Gonad on the left } \\
\cline { 2 - 3 } \cline { 5 - 6 } & $\begin{array}{c}\text { No. of testis } \\
\text { gonoducts }\end{array}$ & $\begin{array}{c}\text { No. of ovary } \\
\text { gonoducts }\end{array}$ & & $\begin{array}{c}\text { No. of testis } \\
\text { gonoducts }\end{array}$ & $\begin{array}{c}\text { No. of ovary } \\
\text { gonoducts }\end{array}$ \\
\hline H. aurantium $(n=40)^{1)}$ & $4.4 \pm 0.7$ & $3.5 \pm 0.6$ & & $3.7 \pm 0.7$ & $3.2 \pm 0.4$ \\
H. roretzi $(n=20)^{2)}$ & $8.4 \pm 0.7$ & $7.4 \pm 1.1$ & & $7.4 \pm 1.2$ & $6.8 \pm 1.4$ \\
\hline
\end{tabular}

${ }^{1)}$ In case of $H$, aurantiun, 10 samples were collected in September and October, 2015 and 2016, respectively.

${ }^{2)}$ In case of $H$, roretzi, 10 samples were collected in November and December 2015, respectively. 


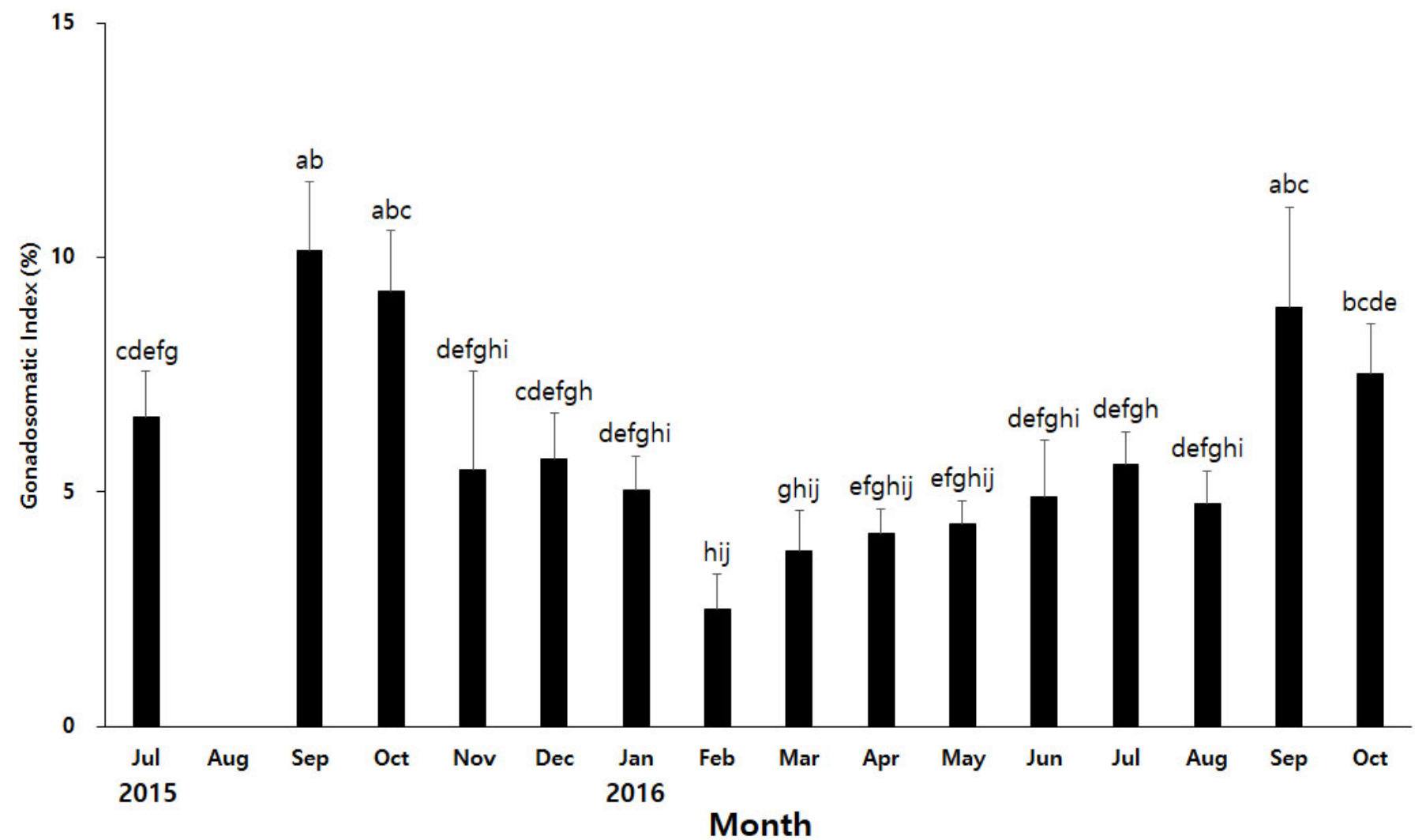

Fig. 2. Seasonal changes in gonadosomatic index (mean $\pm S D, n=10$ ) of the ascidian Halocynthia aurantium. Means not sharing the same superscripts are significantly $(p<0.05)$ different from each other. Samples were not available in August 2015.

\section{REFERENCES}

Bates WR (2011) Environmental factors affecting reproduction and development in ascidians and other protochordates. Can J Zool 83:51-61.

Choi YJ, Lee CH, Rho S, Lee YD (2004) Reproductive cycle and spawning rhythm of the ascidian, Halocynthia hilgendorf ritteri. Korean J Biol Sci 8:33-40.

Inazawa T, Okamura Y, Takahashi K (1998) Basic fibroblast growth factor induction of neuronal ion channel expression in ascidian ectodermal blastomeres. J Physiol 511:347-359.

Katz MJ (1983) Comparative anatomy of the tunicate tadpole, Ciona intestinalis. Biol Bull 164:127.

Kim BS, Bang JD, Ryu HY, Hong JP, Chung EY (2001) Gametogenesis, gonadal development and maturation of the sea squirt, Halocynthia roretzi. Dev Reprod 5:137-144.

Kim HJ, Park JS, Park KH, Shin YK, Park KI (2014) The kinetoplastid parasite Azumiobodo hoyamushi, the causative agent of soft tunic syndrome of the sea squirt Halocynthia roretzi, resides in the East Sea of Korea.J Invertebr Pathol 116:36-42.

Kim GJ (2020) Embryonic development and metamorphosis of the ascidian Halocynthia aurantium. J Mar Life Sci 5:58-63.

Kim JO, Choi SS, Seo YB, Shin J, Yang JY, Kim GD (2021) Complete mitochondrial genome of sea peach Halocynthia aurantium (Stolidobranchia: Pyuridae) from Korea. Mitochondrial DNA B Resour 6:1007-1008.

Kowalevsky AO (1866) Entwicklungsgeschichte der Einfachen Ascidien. Kaiserliche Akademie 
der Wissenschaften, St. Petersburg, Russia, pp 1-19.

Kumagai A, Suto A, Ito H, Tanabe T, Song JY, Kitamura S, Hirose E, Kamaishi T, Miwa S (2011)

Soft tunic syndrome in the edible ascidian Halocynthia roretzi is caused by a kinetoplastid protist. Dis Aquat Organ 95:153-161.

Lambert G, Karney RC, Rhee WY, Carman MR (2016) Wild and cultured edible tunicates: A review. Manag Biol Invasion 7:59-66.

Lemaire P (2009) Unfolding a chordate developmental program, one cell at a time: Invariant cell lineages, short-range inductions and evolutionary plasticity in ascidians. Dev Biol 332:48-60.

Nguyen TTT, Taniguchi N, Nakajima M, Na-Nakorn U, Sukumasavin N, Yamamoto K (2007) Aquaculture of sea-pineapple, Halocynthia roretzi in Japan. Aquac Asia Mag 12:21-23.

Nishida H (2005) Specification of embryonic axis and mosaic development in ascidians. Dev Dyn 233:1177-1193.

Rho BJ, Lee JE (1991) A systematic study on the ascidians in Korea. Korean J Syst Zool 7:195-220. Shenkar N, Swalla BJ (2011) Global diversity of Ascidiacea. PLOS ONE. 6:e20657.

Shin YK, Nam KW, Park KH, Yoon JM, Park KI (2014) Quantitative assessment of Azumiobodo boyamushi distribution in the tunic of soft tunic syndrome-affected ascidian Halocynthia roretzi using real-time polymerase chain reaction. Parasit Vectors 7:539.

Van Name WG (1945) The North and South American Ascidians. American Museum of Natural History, New York, NY, p. 362. 
